\title{
Evaluating the utility of camera traps in field studies of predation
} \author{
Juan M Guayasamin ${ }^{6}$, David W Pfennig ${ }^{1}$ \\ 1 Department of Biology, University of North Carolina at Chapel Hill, Chapel Hill, North Carolina, United States \\ 2 North Carolina Museum of Natural Sciences, Raleigh, North Carolina, United States \\ 3 Facultad de Estudios Superiores Iztacala, Universidad Nacional Autónoma de México, Tlalneplanta, Mexico \\ 4 Facultad de Ciencias de Medio Ambiente, Universidad Tecnológica Indoamérica, Quito, Ecuador \\ 5 Department of Ecology and Evolutionary Biology, University of Arizona, Tucson, Arizona, United States \\ ${ }^{6}$ Colegio de Ciencias Biológicas y Ambientales, Universidad San Francisco de Quito, Quito, Ecuador \\ Corresponding Author: Christopher K Akcali \\ Email address: akcali@live.unc.edu
}

Christopher K Akcali Corresp., 1,2 , Hibraim Adán Pérez Mendoza ${ }^{3}$, David Salazar-Valenzuela ${ }^{4}$, David W Kikuchi ${ }^{5}$,

Artificial prey techniques-wherein synthetic replicas of real organisms are placed in natural habitats-are widely used to study predation in the field. We investigated the extent to which videography could provide additional information to such studies. As a part of studies on aposematism and mimicry of coral snakes (Micrurus) and their mimics, observational data from 109 artificial snake prey were collected from video-recording camera traps in three locations in the Americas (terra firme forest, Tiputini Biodiversity Station, Ecuador; premontane wet forest, Nahá Reserve, Mexico; longleaf pine forest, Southeastern Coastal Plain, North Carolina, USA). During 1,536 camera days, a total of 268 observations of 20 putative snake predator species were recorded in the vicinity of artificial prey. Predators were observed to detect artificial prey 52 times, but only 21 attacks were recorded. Mammals were the most commonly recorded group of predators near replicas (243) and were responsible for most detections (48) and attacks (20). There was no difference between avian or mammalian predators in their probability of detecting replicas nor in their probability of attacking replicas after detecting them. Bite and beak marks left on clay replicas registered a higher ratio of avian:mammalian attacks than videos registered. Approximately $61.5 \%$ of artificial prey monitored with cameras remained undetected by predators throughout the duration of the experiments. Observational data collected from videos could be leveraged to make more robust inferences on the relative fitness of different prey phenotypes, predator behavior, and the relative contribution of different predator species to selection on prey. However, we estimate that the level of predator activity necessary for the benefit of additional information that videos provide to be worth their financial costs is achieved in less than $20 \%$ of published artificial prey studies. Although we suggest future predation studies 
employing artificial prey to consider using videography as a tool to inspire new, more focused inquiry, the investment in camera traps is unlikely to be worth the expense for most artificial prey studies until the cost:benefit ratio decreases. 
1 Evaluating the utility of camera traps in field studies of predation

2

3 Christopher K. Akcali1 ${ }^{1,2,7}$, Hibraim Adán Pérez Mendoza ${ }^{3}$, David Salazar-Valenzuela ${ }^{4}$, David W.

4 Kikuchi $^{5}$, Juan M. Guayasamin ${ }^{4,6}$, and David W. Pfennig ${ }^{1}$

5

$6{ }^{1}$ Department of Biology, University of North Carolina, Chapel Hill, NC, USA

7

$8 \quad{ }^{2}$ North Carolina Museum of Natural Sciences, Raleigh, NC, USA

${ }^{3}$ Laboratorio de Ecología Evolutiva y Conservación de Anfibios y Reptiles, Facultad de Estudios

Superiores Iztacala, Universidad Nacional Autónoma de Mexico, Tlalneplanta, Mexico.

${ }^{4}$ Centro de Investigación de la Biodiversidad y Cambio Climático (BioCamb), Facultad de

Ciencias de Medio Ambiente, Ingeniería en Biodiversidad y Recursos Genéticos, Universidad

Tecnológica Indoamérica, Quito, Ecuador

16

${ }^{5}$ Department of Ecology and Evolutionary Biology, University of Arizona, Tucson, AZ, USA

${ }^{6}$ Universidad San Francisco de Quito (USFQ), Colegio de Ciencias Biológicas y Ambientales, COCIBA, Instituto de Investigaciones Biológicas y Ambientales BIÓSFERA-USFQ,

$23{ }^{7}$ Corresponding author: 
24

25

26

27

28

29

Christopher K. Akcali

E-mail address: akcali@1ive.unc.edu

\section{Abstract}

Artificial prey techniques - wherein synthetic replicas of real organisms are placed in natural habitats - are widely used to study predation in the field. We investigated the extent to which videography could provide additional information to such studies. As a part of studies on aposematism and mimicry of coral snakes (Micrurus) and their mimics, observational data from 109 artificial snake prey were collected from video-recording camera traps in three locations in the Americas (terra firme forest, Tiputini Biodiversity Station, Ecuador; premontane wet forest, Nahá Reserve, Mexico; longleaf pine forest, Southeastern Coastal Plain, North Carolina, USA).

During 1,536 camera days, a total of 268 observations of 20 putative snake predator species were recorded in the vicinity of artificial prey. Predators were observed to detect artificial prey 52 times, but only 21 attacks were recorded. Mammals were the most commonly recorded group of predators near replicas (243) and were responsible for most detections (48) and attacks (20).

There was no difference between avian or mammalian predators in their probability of detecting replicas nor in their probability of attacking replicas after detecting them. Bite and beak marks

2 left on clay replicas registered a higher ratio of avian:mammalian attacks than videos registered. Approximately $61.5 \%$ of artificial prey monitored with cameras remained undetected by predators throughout the duration of the experiments. Observational data collected from videos could be leveraged to make more robust inferences on the relative fitness of different prey 
46 phenotypes, predator behavior, and the relative contribution of different predator species to

47 selection on prey. However, we estimate that the level of predator activity necessary for the

48 benefit of additional information that videos provide to be worth their financial costs is achieved

49 in less than $20 \%$ of published artificial prey studies. Although we suggest future predation

50 studies employing artificial prey to consider using videography as a tool to inspire new, more

51 focused inquiry, the investment in camera traps is unlikely to be worth the expense for most

52 artificial prey studies until the cost:benefit ratio decreases.

53

\section{Introduction}

Studies of predator-prey interactions are often difficult since natural predation events are challenging to observe (Irschick and Reznick, 2009). Moreover, the ability of the rare observation of single predation events to provide general insights into predator-prey interactions is inherently limited. To overcome both difficulties, artificial replicas of prey species are commonly used to study predation in the wild. Such facsimiles allow key features of prey phenotypes (e.g., color, pattern, shape, or size) to be easily manipulated and produced in large numbers, thereby allowing predation to be studied in diverse natural populations (Irschick and Reznick, 2009). Generally, these studies involve constructing replicas (e.g., of pre-colored, nontoxic clay) bearing different colors, patterns, and shapes and placing several hundred of these replicas in natural habitats, where they are exposed to predation by naturally occurring, freeranging predators. After a pre-determined period of time, each replica is scored as attacked or not based on the number and type of marks left on it. Conclusions are then drawn based on the patterns of attacks across phenotypes and/or habitats. Such artificial prey techniques have been used to address a wide variety of evolutionary and ecological questions, ranging from predator 
psychology to aposematism and mimicry (reviewed in Bateman et al., 2017). These studies have been used to measure predator-mediated natural selection on diverse taxa, including insects (Lövei and Ferrante, 2017), fish (Caley and Schluter, 2003), frogs (Saporito et al., 2007), salamanders (Kuchta, 2005), turtles (Marchand et al., 2002), lizards (Stuart-Fox et al., 2003), snakes (Pfennig et al., 2001), birds (Ibáñez-Alamo et al., 2015), and mice (Vignieri et al., 2010).

This traditional approach of using replicas to study predation in the field has three major shortcomings. First, predation attempts - and the identity of the predators - are inferred (Irschick and Reznick, 2009). Although most marks left by predators permit broad classification of predator type (e.g., beak imprints indicate avian predation), they rarely permit predators to be identified to species (Irschick and Reznick, 2009). Furthermore, replicas can be easily removed by predators, making it impossible to determine if predation even occurred. Second, only a subset of interactions between replicas and predators can be assessed from marks left on replicas (Irschick and Reznick, 2009). For example, predators might detect the replicas and decide not to attack them (Willink et al., 2014). Most studies consider all replicas not bearing attack marks as equivalent in statistical analyses, but a variety of factors can affect the probabilities that predators detect a replica as well as not attack a replica after detecting it. Third, replicas are unlikely to sample all potential predators (Irschick and Reznick, 2009). Predators that rely heavily on movement (e.g., felids) or smell (e.g., canids) to detect prey might ignore motionless or odorless replicas (Irschick and Reznick, 2009). In sum, new and improved insight into predation could be gained from artificial prey studies if additional information on the identity and behavior of predator species could be collected.

Camera trapping technology could provide a potentially useful tool for field studies of predation. A camera trap consists of a remotely activated camera that is equipped with a motion 
92 or an infrared sensor (some also use a light beam as a trigger). This technology has been used in

93 ecological research for decades (Savidge and Seibert, 1988; Griffiths and van Schalk, 1993;

94 O’Connell et al., 2011; Burton et al., 2015), typically to detect or survey the abundance of

95 naturally occurring animals. Although several field studies of predation have experimented with

96 camera trapping techniques, most of these studies have used still images to monitor predator

97 activity (e.g., Picman, 1987; Paluh et al., 2015; Ho et al., 2016; Hanmer et al., 2017) and only a

98 few have used video (Thompson and Burhans, 2004; Latif et al., 2012; Sato et al., 2014; Willink

99 et al., 2014; Jedlikowski et al., 2015; Dziadzio et al., 2016; Figure 1). Most these studies using

100 video to monitor predator activity near artificial prey have been conducted on small spatial scales

101 (e.g., at one or a few sites with similar habitat) and have only used videos to aid the identification

102 of predators attacking prey.

103 Here, we studied the ability of camera trap videos to provide additional information to

104 field studies of predation employing artificial prey. The "prey" in our studies are highly

105 venomous New World coral snakes and various harmless lookalikes, which are aposematic and

106 mimetic prey, respectively, bearing conspicuous phenotypes that have long been thought to

107 facilitate the evolution of avoidance behaviors in predators (Bates, 1862; Smith, 1975; Smith,

108 1977; Figure 2). We used camera traps to extract observational data from three independent

109 artificial prey field experiments (Akcali et al., 2018; Supplementary Data). We did so to quantify

110 the frequency at which predators encounter, detect, and attack artificial prey. Using these data,

111 we asked the following questions. First, what are the relative frequencies at which predators

112 encounter, detect, and attack replicas? Second, how do the frequency of encounters, detections,

113 and attacks by predators vary temporally? Third, how does predator type, avian versus mammal,

114 affect the probability that predators detect and attack artificial prey? Fourth, how does the 
115 frequency at which predators encounter, detect, and attack prey vary between predator species?

116 Fifth, how do clay marks and videos differ in their ability to register avian versus mammalian

117 predation attempts? After answering these questions, we conclude by discussing some of the

118 costs and benefits of incorporating videography into field studies of predation.

119

120 Materials and Methods

\section{Ethics Statement}

122 Data collection used non-invasive, remotely-triggered camera traps and hence did not involve

123 direct contact or interaction with animals. The clay used in all experiments is nontoxic.

124 Fieldwork was done under the following permits: Ecuador - N 002-017 IC-FAU-DNB/MA;

125 Mexico - SGPAJDGVS/09347/16. No permits were required in North Carolina, USA.

\section{$127 \quad$ Field Experiments}

128 Three field experiments using clay replicas of various species of coral snakes and their presumed

129 mimics (Figure 2; Table S1) were conducted at three separate locations in the Americas (Figure

130 3). The first experiment was conducted in February 2017 in Amazonian lowland rainforest at

131 Tiputini Biodiversity Station, Orellana, Ecuador ( $0^{\circ} 37^{\prime} \mathrm{S}, 7^{\circ} 16^{`} \mathrm{~W}, 190-270 \mathrm{~m}$ asl; Table 1).

132 This experiment is a part of a larger study that seeks to understand the causes of diversity in

133 aposematism. In this experiment specifically, the aim was to characterize the pattern of selection

134 on a set of aposematic phenotypes in a region where coral snake diversity is high. The second

135 experiment was conducted from June to July 2017 in premontane wet rainforest at Nahá Reserve,

136 Municipality of Ocosingo, Chiapas, México ( $16^{\circ} 58^{`} \mathrm{~N}, 91^{\circ} 35^{\prime} \mathrm{W}, 800-1200 \mathrm{~m}$ asl; Table 1). 
137 The goal of this experiment was to test the "multiple models hypothesis" of imprecise mimicry,

138 which proposes that mimics might evolve imprecise mimicry as a consequence of a selective

139 trade-off to resemble multiple model species (Edmunds, 2000). The third experiment was

140 conducted from October to November 2017 in longleaf pine forests of the Sandhills and Coastal

141 Plain of North Carolina, USA ( $\sim 34^{\circ} 45^{\prime} \mathrm{N}, 7^{\circ} 32^{\prime} \mathrm{W}, 0-150 \mathrm{~m}$ asl; Table 1$)$. This experiment was

142 a part of a larger study that tested whether a coral snake species and its mimics were engaged in

143 a coevolutionary arms race (Akcali et al., 2018).

144 Clay replicas in all experiments were constructed using pre-colored, odorless, nontoxic

145 Sculpey III modeling clay. Measurements of preserved snake specimens from several museums

146 (see the specific museum collections listed in Appendix S1) and photographs of live specimens

147 were used to design prey phenotypes in each experiment. Replicas in all experiments were 1-cm

148 in diameter, but varied in length (Table 1). Because each field experiment was a part of its own

149 independent study, the experiments varied in several ways (Table 1). All damaged replicas were

150 replaced with new replicas during each experiment if transects where checked before their

151 designated date of retrieval (Table 1). Sampling effort for each field experiment in terms of

152 replica days was calculated by multiplying the number of days that replicas were left in the field

153 by the total number of replicas that were placed in the field. The latter includes the number of

154 replicas in front of cameras (regardless as to whether the camera was functional or not) as well as

155 the number of replicas without cameras.

156

157 Camera Trapping

158 We used several relatively inexpensive $(<\$ 100$ each) digital camera traps (Spypoint Force 10,

159 Scout Guard SG560V-31B, ANNKE C303, Bestguarder DTC-880V) triggered by an infrared 
160 motion-and-heat detector to obtain observational data on predator activity near replicas during

161 each field experiment. Cameras used a variable number of AA batteries and were equipped with

162 32-gigabyte SD cards. In each experiment, we attached cameras to the trunks of nearby trees and

163 positioned them $\sim 0.75-1 \mathrm{~m}$ above the surface of the ground at an approximately 45 -degree

164 downward angle. In Ecuador and Mexico, cameras were placed randomly among transects,

165 approximately one meter away from single replicas and were set to have a high sensitivity (if

166 sensitivity could be altered). In North Carolina, cameras were placed approximately 2 to $3 \mathrm{~m}$ in

167 front of sets of three replicas in a clustered fashion (i.e., cameras were placed at every set of

168 replicas in two transects and part of a third transect) and were set to have a medium sensitivity.

169 Average distances between cameras were $1.25 \mathrm{~km} \pm 0.817 \mathrm{~km}, 1.37 \mathrm{~km} \pm 0.829 \mathrm{~km}$, and 4.60

$170 \mathrm{~km} \pm 4.11 \mathrm{~km}$ in Ecuador, Mexico, and North Carolina, respectively. Although vegetation that,

171 when blown by wind, might falsely trigger the cameras was cleared prior to arming the cameras,

172 we tended to place cameras at sites that were devoid of such vegetation to minimize disturbance

173 to the habitat. Cameras were programmed to take 60 -second videos when triggered. Videos were

174 associated with data on the location (from GPS), identity of the camera, date, and time. All data

175 collected from camera traps were recorded using data standards developed for the use of camera

176 traps in biodiversity research (Forrester et al., 2016).

177 Sampling effort for each field experiment in terms of camera days was calculated by

178 taking the sum of the total number of days that each camera was functional in the field. In

179 Ecuador, we placed 27 camera traps (13 Spypoint; 10 Scout Guard; 1 ANNKE) in front of

180 replicas for 14 days. Five camera traps ( 5 Spypoint) were placed in front of replicas for 8 days

181 and then moved in front of replicas in other transects for the final 6 days. Three cameras (3 Scout

182 Guard) failed to take video throughout the duration of the field experiment and one camera (1 
183 Spypoint) took video for 10 days until a spider built a dense web in front of the lens, making it 184 impossible to make out any animal activity on video thereafter. Thus, cameras in Ecuador were 185 armed for a total of 402 camera days ([23 cameras x 14 days $]+[1$ camera $\mathrm{x} 10$ days $]+[5$

186 cameras x 8 days] + [5 cameras x 6 days]). In Mexico, we placed 22 camera traps (21 Spypoint; 187 ANNKE) in front of replicas for 30 days. One camera (1 ANNKE) failed to take video 188 throughout the duration of the field experiment. Thus, 21 cameras in Mexico were armed for a 189 total of 630 camera days (21 cameras x 30 days). In North Carolina, we placed 23 cameras (21 190 Spypoint; 1 ANNKE; 1 Bestguarder) in front of replicas for 28 days. Five cameras (4 Spypoint 191 and 1 ANNKE) failed to take video throughout the duration of the field experiment. Thus, 18 192 cameras in North Carolina were armed for a total of 504 camera days (18 cameras x 28 days). In 193 Ecuador and Mexico, replicas in front of cameras were often exposed to predation longer than replicas that were not monitored by cameras (Table 1).

\section{Analyses}

197

All vertebrate species that triggered the cameras were recorded. Although a variety of vertebrate species have been documented to prey on coral snakes and their mimics, including frogs, toads, snakes, caimans, hawks, falcons, kestrels, shrikes, anis, puffbirds, skunks, and mustelids (Roze, 1996; Campbell and Lamar, 2004), we focus on potential avian and mammalian predators in this study as reptiles and amphibians were rarely detected on cameras and would likely not be selective agents for aposematic coloration. Furthermore, we excluded potential rodents and lagomorph predators from analyses, as has often been done in previous studies (e.g., Brodie 1993; Kikuchi and Pfennig 2010), as well as non-predatory passerines, doves, and timamou species, as these species would likely not represent significant threats to real snakes (see list of 
206

207

208

209

210

211

212

213

214

215

216

217

218

219

220

221

222

223

224

225

226

227 228

vertebrate species considered as predators in analyses in Table S1). Although our choice of which species to consider as predators might be inaccurate, our focus in this study is on the ability of camera traps to provide additional information. So although we refer to all species captured on videos that might be snake predators as "predators" throughout the manuscript out of convenience, we recognize that it would be more appropriate to refer to many of these predator species as "potential predators."

We noted whether each video demonstrated an encounter, detection, attack, and avoidance by a predator. Encounters were simply defined as videos that contained a predator. However, we classified videos of predators as belonging to independent encounters if more than 30 minutes had elapsed between consecutive videos of the same species at the same location. We used 30 minutes as a cut-off because visits by herds of peccaries (Tayassu pecari and Peccari tajacu) were typically the longest of any species at any given site among the three experimental locations, but most visits were less than 30 minutes. Thus, when we use the term "videos," we are referring to the unit (i.e., the actual number of videos) that cameras have taken. In contrast, when we use the term "encounter," we are referring to independent records of predator presence that might include several videos. Detections were defined as encounters where a predator clearly detected a replica (i.e., the predator decreased the rapidity of its movement near the replica and directed attention toward the replica either with its eyes or nose). Attacks were defined as detections where a predator bit a replica (Video S1-S7). Avoidances were defined as detections that did not result in an attack (Video S8-S10). Obviously, cases of avoidance may have arisen because a predator failed to recognize a detected replica as a snake but made a decision not to attack. Thus, when we use avoid, we do not make the implicit assumption that predators recognize replicas as snakes. 

were scored in the field as attacked or not attacked, based on the presence or absence of tooth

231

232

233

234

236 and beak marks, or missing (i.e., no trace of the replica was present). At each replica or sets of replicas with cameras, we then tallied the number of encounters, detections, and attacks by predator species using camera trap videos. We classified predator activity and behavior by hour, starting at midnight, to examine diurnal patterns. Diurnal activity and behavioral patterns were sufficiently well marked that statistical tests were not needed. We also asked how likely predators were to detect a replica they had encountered, and to attack a replica they had detected. We modeled the probability that a predator would detect a replica given that it had encountered it - i.e., $\mathrm{P}($ Detection|Encounter) and the probability that a detection would result in an attack - i.e., $\mathrm{P}($ Attack|Detection). To obtain a sample size sufficient for analysis, we pooled data across Ecuador and Mexico to analyze P(Detection|Encounter), and across Ecuador, Mexico, and North Carolina to analyze $\mathrm{P}($ Attack|Detection). We used different datasets for these two analyses because in North Carolina, cameras were directed at triads of replicas rather than individual replicas, making the calculation of $\mathrm{P}($ Detection|Encounter) different from that in Ecuador and Mexico. We used the glmer function in the lme4 package to fit logistic regressions of whether or not each encountered replica was detected (or attacked, in the second model) as a function of whether the predator was a bird or a mammal, with transect and replica identity included as random effects. Analyses at the species level were not possible due to the low sample sizes of individual species.

We also asked whether there was a difference in detecting attacks by birds versus mammals using marks left in clay or videos. We tested whether the proportion of attacks by birds versus mammals differed between clay marks and videos using Fisher's Exact Test. 


\section{Results}

\section{Predator activity patterns}

255 After eliminating videos with no identifiable animal or only with people, we had 1,071 videos.

256 After classifying videos not separated by at least 30 minutes per species at a given site as

257 representing single records, we had 906 encounters. After eliminating encounters by species that

258 were not classified as snake predators, we were left with 268 encounters of 20 predator species

259 (Table 2), which included 25 encounters of 6 avian predator species (6 families; Table 2) and

260243 encounters of 14 mammalian predator species (8 families; Table 2).

261 Across all experimental locations, we found no difference between avian or mammalian

262 predators in their probability of detecting replicas after encounter in Ecuador and Mexico (Figure

2634 ; Likelihood ratio test; $\chi_{1}^{2}=0.2 ; p=0.79$ ). We found no difference between avian or mammalian

264 predators in their probability of attacking replicas after detection in Ecuador, Mexico, and North

265 Carolina (Figure 4; Likelihood ratio test; $\chi_{1}^{2}=0.01 ; \mathrm{p}=0.92$ ). In total, videos captured 21 attacks 266 and 31 avoidances (Table 3).

267 The frequency of encounters increased approximately 5 and 12 times more rapidly than

268 the frequency of detections and attacks, respectively, as a function of camera trapping effort

269 (Figure S1). The frequency of detections increased approximately 2.4 times more rapidly than 270 the frequency of attacks (Figure S1).

271 The timing of encounters, detections, and attacks varied among experimental locations

272 (Figure 5). In Ecuador, activity peaked during daylight hours (Figure 5). In contrast, in North

273 Carolina, activity peaked at night, with most attacks occurring just after sunset (Figure 5). In 
274 Mexico, predator encounters were more common at night; however, most detections and attacks

275 occurred during the day (Figure 5).

276

277 Variation among predator species

278 The frequency and timing of encounters, detections, and attacks also varied among predator

279 species. In Ecuador, activity was dominated by collared peccaries (Pecari tajacu), white-lipped

280 peccaries (Tayassu pecari), and gray-winged trumpeters (Psophia crepitans) (80.5\% of

281 encounters, $88.9 \%$ of detections, and $100 \%$ of attacks; Table 2). In Mexico, activity was

282 dominated by common opossums (Didelphis marsupialis), gray foxes (Urocyon

283 cinereoargenteus), and nine-banded armadillos (Dasypus novemcinctus) $(72.2 \%$ of encounters,

$284100 \%$ of detections and attacks; Table 2). In North Carolina, activity was mostly restricted to

285 black bears (Ursus americanus), common racoons (Procyon lotor), Virginia opossums

286 (Didelphis virginiana), and gray foxes (97.3\% of encounters, $100 \%$ of detections and attacks;

287 Table 2).

288

Eleven of 20 predator species (five bird species and six mammal species) that were

289

290

291

292

293

294

295

296

encountered never detected replicas (Table 2). Each of these species was encountered 10 times or less (mean \pm s.d.: $2.27 \pm 2.72$; median $=2$; Table 2$)$. In contrast, nearly all of the nine species of predator (one bird species and eight mammal species) that detected replicas were commonly encountered near replicas (mean \pm s.d.: $26.11 \pm 22.40$; median $=19$; Table 2). Species with the highest detection per encounter rates were Pecari tajacu (42.3\%), Ursus americanus (36.8\%), and Urocyon cinereoargenteus (29.7\%) (Table 2). Species with the lowest detection per encounter rates included ocelots (Leopardus pardalis; 0.0\%), Didelphis marsupialis (5.2\%), and Dasypus novemcinctus (11.1\%) (Table 2). Of species that detected replicas at least five times, the 
297 highest attack per detection rates were by Urocyon cinereoargenteus (72.3\%) and Ursus

298 americanus (71.4\%) (Table 2). Species with the lowest attack per detection rates were Pecari 299 tajacu (0.0\%) and Procyon lotor (23.5\%) (Table 2).

300

\section{Clay marks vs. videos}

302 Using marks left in clay replicas, we observed 33 avian attacks and 21 mammal attacks in

303 Ecuador, 78 avian attacks and 92 mammal attacks in Mexico, and 16 avian attacks and 198

304 mammal attacks in North Carolina (Figure 6). A total of 18, 57, and 12 replicas from Ecuador,

305 Mexico, and North Carolina, respectively, were scored as missing, as we were not able to locate

306 any trace of these replicas at their original location (Figure 6). Using video, we observed one

307 avian and one mammal attack in Ecuador, seven mammal attacks in Mexico, and 12 mammal

308 attacks in North Carolina (Figure 7; Table 3). We found that marks left in clay replicas revealed

309 a significantly higher ratio of avian:mammalian attacks than camera trap videos (Fisher's Exact

310 Test; $\mathrm{p}=0.012$ ).

311 Across all experimental locations, 13 replicas that were registered as attacked based on

312 videos were also scored as attacked based on clay marks (Table 3). Eight replicas that were

313 registered as attacked based on videos were not scored as attacked using clay marks (Table 3). In

314 five of these cases, replicas were scored as missing in the field as videos confirmed that

315 predators removed replicas from their original location. In two cases, replicas were present but

316 no impressions indicative of bite marks were visible. In a final case, one predator attacked a

317 replica without destroying it and another predator later attacked the same replica; thus, this

318 replica was scored as having two attacks according to video but only one attack was scored based

319 on clay marks. No evidence of attacks by predators was obtained from videos for six replicas that 
were scored as attacked based on clay marks (Table 3 ).

321

\section{Discussion}

323 We evaluated whether camera trap videos can provide additional information that could be

324 useful to field studies of predation employing artificial prey. Field studies typically rely on the

325 relative frequencies of clay marks on different prey phenotypes to infer avoidance behaviors of

326 predators (e.g., Noonan and Comeault, 2008; Marek et al., 2011; Dell'Aglio et al., 2016;

327 Kristiansen et al., 2018). Previous predation field studies that have employed camera traps have

328 generally used photography (Figure 1), have been conducted on small scales, and have primarily

329 employed cameras for the sole purpose of identifying predators attacking artificial prey. Our

330 observational data collected from three field experiments conducted in three separate locations

331 show that camera trap videos can be used to provide benefits to field studies of predation beyond

332 predator identification.

333

334

encounter, detect, and attack replicas could be gathered using videography. These data could be

used in a variety of ways to enhance predation studies employing artificial prey.

First, these observational data could be used to make more robust evaluations of the

relative fitness of different prey phenotypes. For example, in heavily shaded habitats such as the

tropical forests where field experiments were conducted in Ecuador and Mexico, the warning

coloration of coral snakes and their mimics is unlikely to provide protection from predation at

night given that the visibility of their color patterns to predators should be low (Kelber et al.,

341 2017). Information on warning coloration is therefore unlikely to factor into decisions by

342 predators to attack replicas at night in such habitats. As a result, an analysis that omitted the two 
343 attacks that were observed at night in Mexico (Figure 5C) would provide a more robust test of

344 how warning coloration factors into prey-selection decisions by predators. Similarly, because

345 different color pattern phenotypes might vary in their conspicuousness to predators, differences

346 in predation rates could be driven by both variation in prey preference and variation in visual

347 detection rate (Stuart et al., 2012; Rojas et al., 2014). Variation in visual detection rate has been

348 shown to be an unlikely explanation for differences in predation rates between color pattern

349 phenotypes in at least a few aposematic taxa (Brodie, 1993; Wüster et al., 2004; Buasso et al.,

350 2006; McElroy, 2016). Nevertheless, restricting analyses to replicas that were actually detected

351 would provide more direct tests of the fitness consequences associated with different prey

352 phenotypes, given that the fitness benefits of aposematic prey should only be realized after

353 predators have detected prey. Replicas monitored by cameras across all field experiments more

354 often remain undetected than detected throughout the monitoring period (Table 3). Thus, field

355 studies of aposematic prey that limited analyses to the subset of detected replicas could

356 potentially benefit from increased statistical power to resolve differences in predation between

357 phenotypes.

358 Second, these observational data could be used to more precisely characterize how

359 different predators contribute to selection on prey phenotypes. Although predator communities as

360 a whole did not have a tendency to attack or avoid replicas following detection (Figure 4), the

361 data tentatively suggest that predators might vary in their behavioral responses to aposematic

362 phenotypes (Table 2). At least one predator species, P. tajacu, had a tendency to

363 disproportionately avoid coral snake phenotypes, while most other predator species (e.g., $U$.

364 cinereoargenteus) attacked them (Table 2). Given that P. tajacu is largely diurnal and is one of

365 the most common predators at Tiputini Biodiversity Station in Ecuador (Blake et al., 2012; Blake 
366

367

368

369

370

371

372

373

374

375

376

377

378

379

380

381

382

383

384

385

386

387

388

and Loiselle, 2018), their contribution to selection might be disproportionately small relative to their abundance. Likewise, U. cinereoargenteus is one of the more common mammals encountered during camera trap surveys conducted in the Carolina Sandhills (Akcali et al., unpublished data), where they are largely crepuscular and nocturnal like the coral snake mimics with which they co-occur (Palmer and Braswell, 1995; Whitaker, 1998). Consequently, $U$.

cinereoargenteus might have been a key predator in facilitating the recent rapid evolution of a coral snake mimic in the Carolina Sandhills (Akcali and Pfennig, 2014). However, these claims remain speculative until additional data are gathered that permit a more robust characterization of the prey selection functions of these predators.

Third, observational data from videos could allow more data to be collected from artificial prey experiments. When no traces of a replica can be located at their original location, researchers often conservatively score such replicas as missing and omit them from subsequent analyses (e.g., Kikuchi and Pfennig, 2010; Choteau and Angers, 2011; Lawrence et al., 2018). However, videography — more often than photography — can provide conclusive evidence of cases where missing replicas were due to removal by predators. Across all three experiments, videos revealed that all six replicas that were scored as missing in the field were actually removed by predators. Given that a total of 87 replicas were scored as missing across all three field experiments (Figure 6), the potential for videos to rescue lost data might be substantial. Fourth, these observational data could provide insight into the extent to which artificial prey approaches sample a biased subset of the predator community. Several studies have suggested that avian predators should be more important selective agents on coral snake color patterns than mammalian predators, especially in the tropics (Brodie, 1993; Brodie and Janzen, 1995; Hinman et al., 1997). During our field experiments, avian predators were substantially 
389

390

391

392

393

394

395

396

397

398

399

400

401

402

403

404

405

406

407

408

409

410

411

underrepresented on videos relative to the frequency at which their beak marks were recorded on replicas that were not monitored by cameras (Figure 6, Figure 7). This pattern is generally consistent with most camera trapping studies that report capture rates for both mammalian and avian species, which have found that avian species tend to have lower capture rates on cameras (e.g., Stein et al., 2008; Blake et al., 2011; Naing et al., 2015). Thus, it is not clear whether this difference in the representation of avian predators in videos and clay marks reflects the fact that avian predators often moved too fast to be recorded on videos, that avian predators detected replicas outside the field of view of the cameras and actively avoided cameras as a consequence, or alternatively, that this was simply due to the low number of cameras relative to replicas that were not monitored by cameras (Table 1). Avian predators and some mammalian predator species (e.g., L. pardalis, Table 2) might have extremely low rates of detections relative to encounters. Predators with low detection rates might not be capable of being sampled using artificial prey approaches either because replicas do not provide the cues needed for predators to easily detect them or because these predators detect replicas but do not classify them as edible prey. In such cases, laboratory experiments might be necessary to definitely characterize the ability of predators to detect replicas (Rößler et al., 2018). Predator species that are infrequently captured on video would be particularly important for controlled experiments given that low encounter rates ultimately preclude assessment of predator sampling biases of artificial prey. Thus, videography can provide some additional information for artificial prey studies, but is it worth the costs? An informal survey of predation studies employing artificial prey (see Figure 1 for search details) revealed that — out of studies that report both sample sizes and the length of time artificial prey were exposed to natural predators $(N=441$ studies $)$ - most employ large numbers of replicas (mean \pm s.d. $=482 \pm 712$, median $=300)$ for an exposure period close 
412 to two weeks (mean \pm s.d. $=12.7 \pm 9$ days, median $=12$ days). Although the amount of

413 information provided by videos varied substantially among our experiments (Figure 7, Table 3),

414 one camera, averaged across all three experiments, obtained 0.18 encounters, 0.04 detections,

415 and 0.01 attacks per day by species that we classified as predators. If these frequencies are

416 calculated over a single transect consisting of 30 video-monitored replicas, which would

417 represent $10 \%$ of the total replicas employed in the median artificial prey experiment, over a 12-

418 day study timeline, representing the length of the median artificial prey experiment, a total of

41965.3 encounters, 13.7 detections, and 4.8 attacks would be expected to be observed. If each

420 camera were to cost $\$ 100$, each additional encounter, detection, and attack in terms of camera

421 expenses would cost approximately $₫ 46, \$ 219$, and $\$ 625$, respectively. If these figures were to be

422 calculated for avian predators alone, a total of 7.1 encounters, 1.2 detections, and 0.3 attacks

423 would be expected for a single 30-replica transect monitored by cameras for 12 days, with each

424 additional encounter, detection, and attack requiring $\$ 423, \$ 2,500$, and $\$ 10,000$, respectively, in

425 camera costs. Thus, obtaining additional information via videography can be relatively expensive

426 even without considering its accompanying logistical and time costs, which are not negligible but

427 relatively minor comparatively speaking (Table S2). Indeed, the cost of cameras that was

428 incurred for each of our field experiments was more than the total cost of conducting any one

429 experiment without cameras (Table S2). The reliability of video recording can impose additional

430 costs, as six out of 18 replicas monitored by cameras bore clay marks by predators but no

431 evidence of predation was captured on video.

432 In other systems, however, these costs might not be quite as high. If the percent of

433 replicas attacked per day is used as a proxy for predator activity, the average predator activity

434 level from our three experiments (ca. 1\% replicas/day) was lower compared to other artificial 
435 prey studies $($ mean $=6 \%$ replicas $/$ day, median $=4 \%$ replicas $/$ day, $N=424$ studies). If we

436 recalculate the amount of information and costs that would be expected for a single transect of

437 the median artificial prey study (30 camera-monitored replicas for 12 days) assuming that

438 differences in encounters, detections, and attacks are proportional to differences in encounters,

439 detections, and attacks that were estimated in our study, a total of 98 encounters, 20.6 detections,

440 and 7.2 attacks would be expected, with each additional encounter, detection, and attack

441 requiring approximately $\$ 31, \$ 146$, and $\$ 416$, respectively, in camera costs. If these same

442 calculations and assumptions are made using each of the predation rates that have been reported

443 from our informal literature survey, the minimum level of predator activity (in terms of $\%$

444 predation per day) necessary for the purchase of one additional camera to capture an additional

445 encounter, detection, or attack would be approximately $0.01 \%, 0.03 \%$, and $0.08 \%$ replicas/day,

446 respectively (Figure S2). Approximately $68.3 \%$ of artificial prey studies have reported predator

447 activity levels higher than the $0.03 \%$ threshold, whereas only $18.2 \%$ of such studies have

448 reported predator activity levels higher than the $0.08 \%$ threshold. Unless measures are taken to

449 increase the rate at which information could be obtained (e.g., increasing the realism of replicas;

450 Paluh et al. 2014), the benefits of additional information would only be worth the cost of cameras

451 in a minority of systems.

452

453 Conclusions

454 Results from this study provide quantitative estimates of the amount of additional information 455 that camera trap videos could provide to artificial prey studies and demonstrates some of the

456 benefits of using videography over remote photography in artificial prey studies. Across three

457 field experiments, dozens of observations were obtained on the frequency at which predators 
458 encounter, detect, attack, and avoid artificial prey. Observations of predator activity were

459 dominated by mammals. Videography likely underestimates activity by avian predators as marks

460 on artificial prey registered a higher ratio of avian:mammalian attacks than videos. These

461 observational data can be used to estimate the rates and probabilities of encounters, detections,

462 attacks, and avoidances by predators. This information could then be used to conduct more direct

463 tests of the relative fitness of different artificial prey phenotypes as well as provide insight into

464 the relative contribution of different predator species to selection on prey. However, the

465 incorporation of cameras into artificial prey studies that experience low rates of predator activity

466 would be difficult to justify given the current costs of cameras. Nevertheless, videography would

467 still prove useful at smaller scales as a tool to generate new observations that could lead to new

468 questions or ideas for testing.

469

470 Acknowledgements

471 We thank D. Kramer for providing comments that significantly improved the manuscript. We

472 also thank J. Hunter, C. Porter, and one anonymous reviewer for comments. We thank B. Edwin

473 Siurob Espíndola, C. Iván Hernández Herrera, D. Joaquin Sánchez Ochoa, E. Hernández

474 Martínez, S. Jovita González Ramos, J. Vaca Guerrero, and personnel at Tiputini Biodiversity

475 station for help with fieldwork. We thank the Ecuadorian and Mexican government for providing

476 the necessary research permits (Ecuador: $\mathrm{N}^{\circ}$ 002-017 IC-FAU-DNB/MA; Mexico:

477 SGPAJDGVS/09347/16).

478

479 References 
480 Akcali CK, and Pfennig DW. 2014. Rapid evolution of mimicry following local model

481 extinction. Biology Letters 10:20140304 DOI:10.1098/rsbl.2014.0304.

482

483

484

485

486

487

488

489

490

491

492

493

494

495

496

497

498

Akcali CK, Kikuchi DW, and Pfennig DW. 2018. Coevolutionary arms races in Batesian mimicry? A test of the chase-away hypothesis. Biological Journal of the Linnean Society 124:668-676 DOI:10.1093/biolinnean/bly075.

Bateman PW, Fleming PA, Wolfe AK. 2017. A different kind of ecological modelling: the use of clay model organisms to explore predator-prey interactions in vertebrates. Journal of Zoology 301:251-262 DOI:10.1111/jzo.12415.

Bates HW. 1862. Contributions to an insect fauna of the Amazon valley. Lepidoptera: Heliconidae. Transactions of the Linnean Society of London 23:495-566.

Blake JG, Mosquera D, Guerra J, Loiselle BA, Romo D, and Swing K. 2011. Mineral licks as diversity hotspots in lowland forest of eastern Ecuador. Diversity 3:217-234 DOI:10.3390/d3020217.

Blake JG, Mosquera D, Loiselle BA, Swing K, Guerra J, and Romo D. 2012. Temporal activity patterns of terrestrial mammals in lowland rainforest of eastern Ecuador. Ecotropica 18:137-146.

Blake JG, and Loiselle BA. 2018. Annual and spatial variation in composition and activity of terrestrial mammals on two replicate plots in lowland forest of eastern Ecuador. PeerJ 6:e4241 DOI:10.7717/peerj.4241. 
499 Brodie ED. 1993. Differential avoidance of coral snake banded patterns by free-ranging avian 500 predators in Costa Rica. Evolution 47:227-235 DOI:10.1111/j.1558-

501 5646.1993.tb01212.x.

502

503

504

505

506

507

508

509

510

511

512

513

514

515

516

517

518

519

Brodie ED, and Janzen FJ. 1995. Experimental studies of coral snake mimicry: generalized avoidance of ringed snake patterns by free-ranging avian predators. Functional Ecology 9:186-190 DOI:10.2307/2390563.

Buasso CM, Leynaud GC, and Cruz FB. 2006. Predation on snakes of Argentina: effects of coloration and ring pattern on coral and false coral snakes. Studies on Neotropical Fauna and Environment 41:183-188 DOI:10.1080/01650520600630725.

Burton AC, Neilson E, Moreira D, Ladle A, Steenweg R, Fisher JT, Bayne E, Boutin S. 2015. Wildlife camera trapping: a review and recommendations for linking surveys to ecological processes. Journal of Applied Ecology 52:675-685 DOI:10.1111/13652664.12432.

Caley MJ, Schluter D. 2003. Predators favour mimicry in a tropical reef fish. Proceedings of the Royal Society of London B: Biological Sciences 270:667-672 DOI:10.1098/rspb.2002.2263.

Campbell JA, and Lamar WW. 2004. The Venomous Reptiles of the Western Hemisphere. Vol. I. Ithaca: Comstock Publishing Associates.

Chouteau M, and Angers B. 2011. The role of predators in maintaining the geographic organization of aposematic signals. The American Naturalist 178:810-817 DOI:1086/ 662667. 
520 Dell'Aglio DD, Stevens M, and Jiggins CD. 2016. Avoidance of an aposematically coloured

521

522

523

524

525

526

527

528

529

530

531

532

533

534

535

536

537

538

539

540

butterfly by wild birds in a tropical forest. Ecological Entomology 41:627-632 DOI:10. 1111/een.12335.

Dziadzio MC, Smith LL, Chandler RB, and Castleberry SB. 2016. Effect of nest location on gopher tortoise nest survival. Journal of Wildlife Management 80:1314-1322 DOI:10.1002/jwmg.21116.

Edmunds M. 2000. Why are there good and poor mimics? Biological Journal of the Linnean Society 70:459-466 DOI:10.1111/j.1095-8312.2000.tb01234.x.

Forrester T, O’Brien T, Fegraus E, Jansen PA, Palmer J, Kays R, Ahumada J, Stern B, McShea W. 2016. An open standard for camera trap data. Biodiversity Data Journal 4:e10197 DOI:10.3897/BDJ.4.e10197.

Griffiths M, van Schalk CP. 1993. Camera-trapping: a new tool for the study of elusive rain forest animals. Tropical Biodiversity 1:131-135.

Hanmer HJ, Thomas RL, and Fellowes MDE. 2017. Provision of supplementary food for wild birds may increase the risk of local nest predation. Ibis 159:158-167 DOI:10.1111/ibi.12432.

Hinman KE, Throop HL, Adams KL, Dake AJ, McLauchlan KK, McKone MJ. 1997. Predation by free-ranging birds on partial coral snake mimics: the importance of ring width and color. Evolution 51:1011-1014 DOI:10.1111/j.1558-5646.1997.tb03684.x.

Ho S, Schachat SR, Piel WH, and Monteiro A. 2016. Attack risk for butterflies changes with eyespot number and size. Royal Society Open Science 3:150614 DOI:10.1098/150614. 
541 Ibáñez-Álamo JD, Magrath RD, Oteyza JC, Chalfoun AD, Haff TM, Schmidt KA, Thomson RL, 542 Martin TE. 2015. Nest predation research: recent findings and future perspectives. Journal of Ornithology 156:S247-S262 DOI:10.1007/s10336-015-1207-4.

544 Irschick DJ, Reznick D. 2009. Field experiments, introductions, and experimental evolution. In:

545 Garland Jr T, Rose ME, eds. Experimental evolution: concepts, methods, and applications of selection experiments. Berkeley: University of California Press, 173-193.

547

548

549

550

551

552

553

554

555

556

557

558

559

560

561

Jedlikowski J, Brzezinski M, and Chibowski P. 2015. Habitat variables affecting nest predation rates at small ponds: a case study of the Little Crake Porzana parva and Water Rail Rallus aquaticus. Bird Study 62:1-12 DOI:10.1080/00063657.2015.1031080.

Latif QS, Heath SK, and Rotenberry JT. 2012. How avian nest site selection responds to predation risk: testing an 'adaptive peak hypothesis.' Journal of Animal Ecology 81:127138 DOI:10.1111/j.1365-2656.2011.01895.x.

Lawrence JP, Mahony M, and Noonan BP. 2018. Differential responses of avian and mammalian predators to phenotypic variation in Australian brood frogs. PLoS ONE 13:e0195446 DOI:10.1371/journal.pone.0195446.

Lövei GL, Ferrante M. 2017. A review of the sentinel prey method as a way of quantifying invertebrate predation under field conditions. Journal of Insect Science 24:528-542 DOI:10.1111/1744-7917.12405.

Kelber A, Yovanovich C, and Olsson P. 2017. Thresholds and noise limitations of colour vision in dim light. Proceedings of the Royal Society of London B: Biological Sciences 372:20160065 DOI:10.1098/rstb.2016.0065. 
562 Kikuchi DW, and Pfennig DW. 2010. High model abundance may permit the gradual evolution

563

564

565

566

567

568

569

570

571

572

573

574

575

576

577

578

579

580

581

582

of Batesian mimicry: an experimental test. Proceedings of the Royal Society of London B: Biological Sciences 277:1041-1048 DOI:10.1098/rspb.2009.2000.

Kristiansen EB, Finkbeiner SD, Hill RI, Prusa L, and Mullen SP. 2018. Testing the adaptive hypothesis of Batesian mimicry among hybridizing North American admiral butterflies. Evolution 72:1436-1448 DOI:10.1111/evo.13488.

Kuchta SR. 2005. Experimental support for aposematic coloration in the salamander Ensatina eschscholtzii xanthoptica: implications for mimicry of Pacific Newts. Copeia 2005:265271 DOI:10.1643/CH-04-173R.

Marchand MN, Litvaitis JA, Maier TJ, DeGraaf RM. 2002. Use of artificial nests to investigate predation on freshwater turtle nests. Wildlife Society Bulletin 30:1092-1098.

Marek P, Papaj D, Yeager J, Molina S, and Moore W. 2011. Bioluminescent aposematism in millipedes. Current Biology 21:R680-R681 DOI:10.1016/j.cub.2011.08.012.

McElroy MT. 2016. Teasing apart crypsis and aposematism - evidence that disruptive coloration reduces predation on a noxious toad. Biological Journal of the Linnean Society 117:285294 DOI:10.1111/bij.12669.

Naing H, Fuller TK, Sievert PR, Randhir TO, Tha Po SH, Maung M, Lynam AJ, Thaw WN, and Myint T. 2015. Assessing large mammal and bird richness from camera-trap records in the Hukaung Valley of northern Myanmar. Raffles Bulletin of Zoology 63:376-388.

Noonan BP, and Comeault AA. 2008. The role of predator selection on polymorphic aposematic poison frogs. Biology Letters 5:51-54 DOI:10.1098/rsbl.2008.0586. 
583 O’Connell AF, Nichols JD, Karanth KU. 2011. Camera Traps in Animal Ecology: Methods and 584 Analyses. Springer, New York.

585 Palmer WM, and Braswell AL. 1995. Reptiles of North Carolina. Chapel Hill: University of $586 \quad$ North Carolina Press.

587 Paluh DJ, Hantak MM, Saporito RA. 2014. A test of aposematism in the dendrobatid poison frog 588 Oophaga pumilio: the importance of movement in clay model experiments. Journal of 589 Herpetology 48:249-254 DOI:10.1670/13-027.

590

591

592

593

594

595

596

597

598

599

600

601

Paluh DJ, Kenison EK, and Saporito RA. 2015. Frog or fruit? The importance of color and shape to bird predators in clay model experiments. Copeia 103:58-63 DOI:10.1643/CE-13-126.

Peterson RT. 2010. Peterson Field Guide to Birds of Eastern and Central North America. $6^{\text {th }}$ ed. New York: Houghton Mifflin Harcourt.

Pfennig DW, Harcombe WR, Pfennig KS. 2001. Frequency-dependent Batesian mimicry. Nature 410:323 DOI:10.1038/35066628.

Picman J. 1987. An inexpensive camera setup for the study of egg predation at artificial nests. Journal of Field Ornithology 58:372-382.

Ridgely RS, and Greenfield PJ. 2001. The Birds of Ecuador. Vol. II. Ithaca: Cornell University Press.

Rößler DC, Pröhl H, and Lötters S. 2018. The future of clay model studies. BMC Zoology 3:6 DOI:10.1186/s40850-018-0033-6. 
602 Rojas B, Rautiala P, and Mappes J. 2014. Differential detectability of polymorphic warning 603 signals under varying light environments. Behavioural Processes 109:164-172 DOI:10.

604 1016/j.beproc.2014.08.014.

605

606

607

608

609

610

611

612

613

614

615

616

617

618

619

620

621

622

Roze JA. 1996. Coral snakes of the Americas: Biology, Identification, and Venoms. Malabar: Krieger Publishing Company.

Saporito RA, Zuercher R, Roberts M, Gerow KG, Donnelly, MA. 2007. Experimental evidence for aposematism in the Dendrobatid poison frog Oophaga pumilio. Copeia 2007:10061011 DOI:10.1643/0045-8511(2007)7[1006:EEFAIT]2.0.CO;2.

Sato CF, Wood JT, Schroder M, Green K, Osborne WS, Michael DR, and Lindenmayer DB. 2014. An experiment to test key hypotheses of the drivers of reptile distribution in subalpine ski resorts. Journal of Applied Ecology 51:13-22 DOI:10.1111/13652664.12168.

Savidge JA, Seibert TF. 1988. An infrared trigger and camera to identify predators at artificial nests. Journal of Wildlife Management 52:291-294.

Smith SM. 1975. Innate recognition of coral snake pattern by a possible avian predator. Science 187:759-760 DOI:10.1126/science.187.4178.759.

Smith SM. 1977. Coral-snake pattern recognition and stimulus generalization by naïve great kiskadees (Avis: Tyrannidae). Nature 265:535-536 DOI:10.1038/265535a0.

Stein AB, Fuller TK, and Marker LL. 2008. Opportunistic use of camera traps to assess habitatspecific mammal and bird diversity in northcentral Namibia. Biodiversity and Conservation 17:3579-3587 DOI:10.1007/s10531-008-9442-0. 
623 Stuart YE, Dappen N, and Losin N. 2012. Inferring predator behavior from attack rates on prey-

624

625

626

627

628

629

630

631

632

633

634

635

636

637

638

639

640

641

642

replicas that differ in conspicuousness. PLOS ONE 7:e48497 DOI:10.1371/journal.pone. 0048497.

Stuart-Fox DM, Moussalli A, Marshall NJ, Owens IPF. 2003. Conspicuous males suffer higher predation risk: visual modelling and experimental evidence from lizards. Animal Behaviour 66:541-550 DOI:10.1006/anbe.2003.2235.

Thompson III FR, and Burhans DE. 2004. Differences in predators of artificial and real songbird nests: evidence of bias in artificial nest studies. Conservation Biology 18:373-380 DOI:10.1111/j.1523-1739.2004.00167.x.

Vallely A, and Dyer D. 2018. Birds of Central America: Belize, Guatemala, Honduras, El Salvador, Nicaragua, Costa Rica, and Panama. Princeton: Princeton University Press.

Vignieri SN, Larson JG, Hoekstra HE. 2010. The selective advantage of crypsis in mice. Evolution 64:2153-2158 DOI:10.1111/j.1558-5646.2010.00976.x.

Whitaker JO. 1998. Mammals of the Eastern United States. Ithaca: Comstock Publishing Associates.

Willink B, García-Rodríguez A, Bolaños F, Pröhl H. 2014. The interplay between multiple predators and prey colour divergence. Biological Journal of the Linnean Society 113:580-589 DOI:10.1111/bij.12355.

Wilson DE, and Reeder D. 2005. Mammal Species of the World. A Taxonomic and Geographic Reference. $3^{\text {rd }}$ ed. Baltimore: Johns Hopkins University Press. 
643 Wüster W, Allum CSE, Bjargardóttir IB, Bailey KL, Dawson KJ, Guenioui J, Lewis J, McGurk

644 J, Moore AG, Niskanen M, and Pollard CP. 2004. Do aposematism and Batesian mimicry 645 require bright colours? A test, using European viper markings. Proceedings of the Royal Society of London B: Biological Sciences 271:2496-2499 DOI:10.1098/rspb.2004.2894. 


\section{Figure 1}

Field studies of predation.

Number of field studies of predation employing camera traps using different types of monitoring methods and different types of artificial prey. Manuscripts were informally searched in Google Scholar ( http://scholar.google.com ) using a variety of search terms (e.g., artificial prey, artificial nest, clay model, and predation) and taxon terms (e.g., amphibian, bird, butterfly, frog, lizard, salamander, and snake). The search was conducted 23 December 2017.

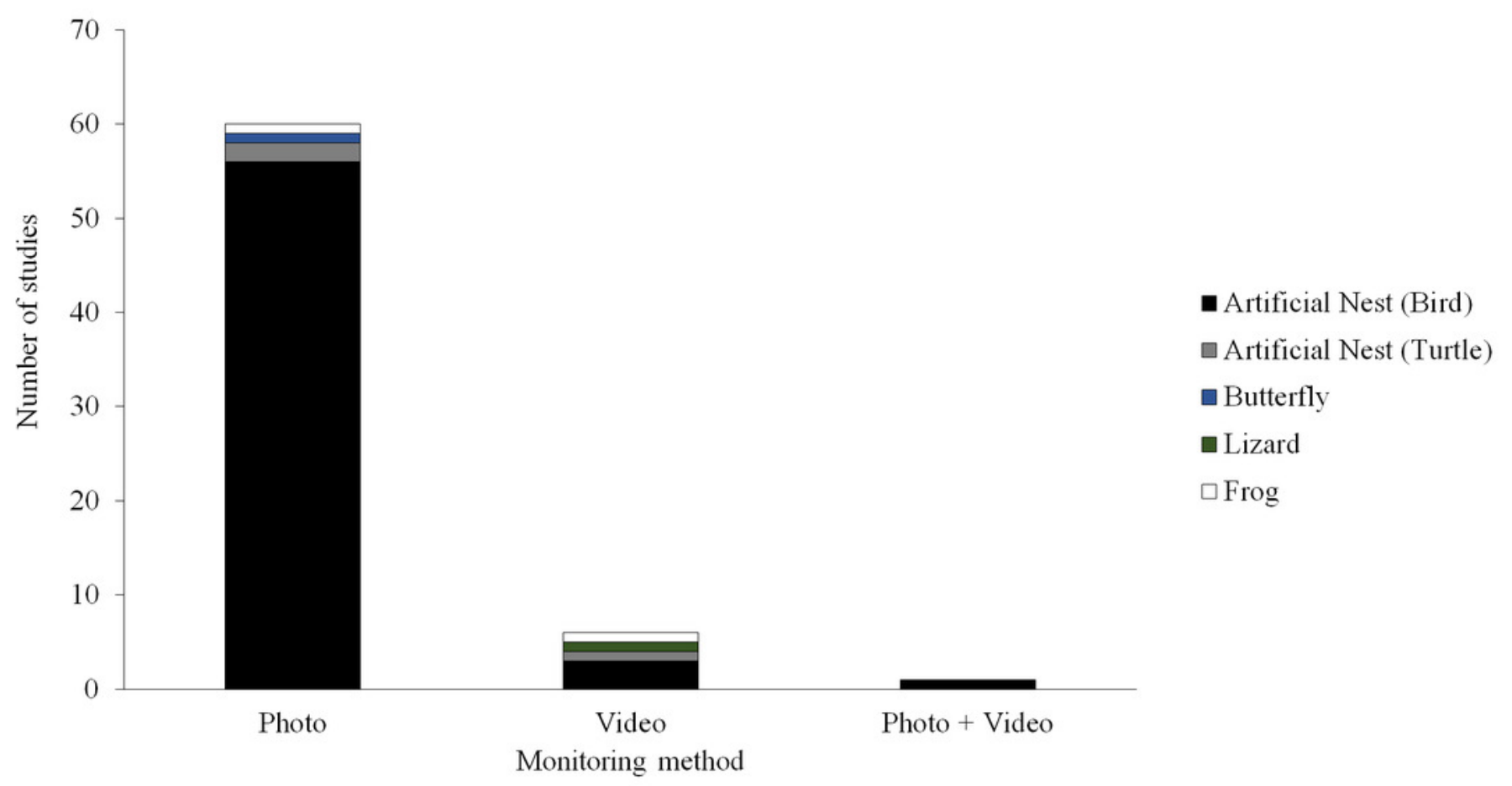




\section{Figure 2}

\section{Study snake species.}

A sampling of images of live snakes $(A, C, E)$ and artificial snake replicas $(B, D, F)$ from each experimental location. (A, B) The South American coral snake (Micrurus lemniscatus) (photo credit: Mike Pingleton), (C, D) the variable coral snake (Micrurus diastema) (photo credit: Eric Centenero Alcalá), and (E, F) the eastern coral snake (Micrurus fulvius) (photo credit: Christopher K. Akcali). Note the bite marks and change in shape caused by a mammalian predation attempt in $\mathrm{D}$. 

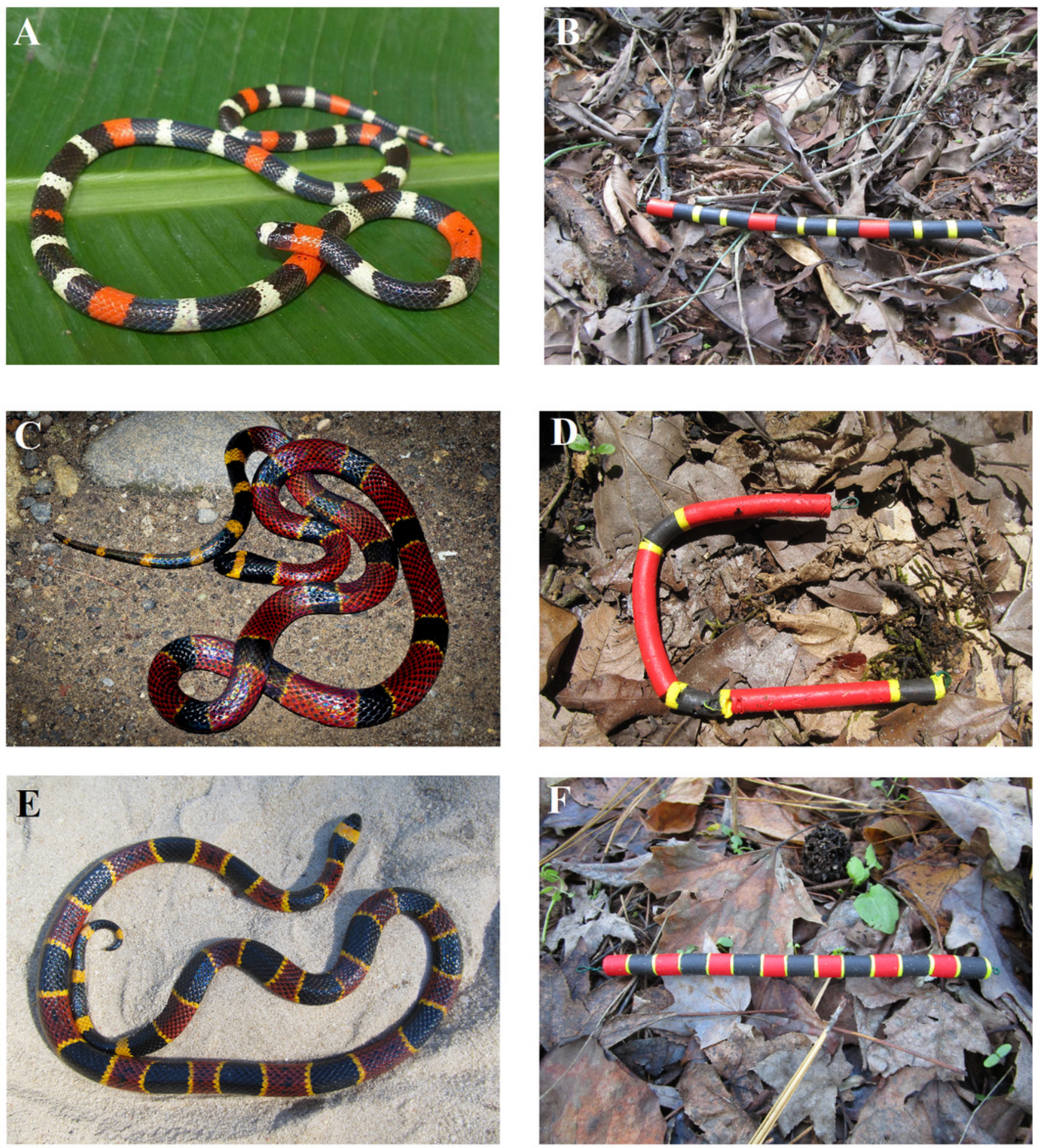


\section{Figure 3}

Study areas.

Camera traps were used to collect observational data on predator behavior in three field experiments, conducted in North Carolina, USA, Mexico, and Ecuador, that were aimed to test hypotheses of aposematism and mimicry. Insets show habitat typical of the study areas: (A) longleaf pine forest, North Carolina, USA (Photo Credit: Christopher K. Akcali); (B) premontane wet forest, Chiapas, Mexico (Photo Credit: Christopher K. Akcali); and (C) terra firme rainforest, Orellana, Ecuador (Photo Credit: Christopher K. Akcali).

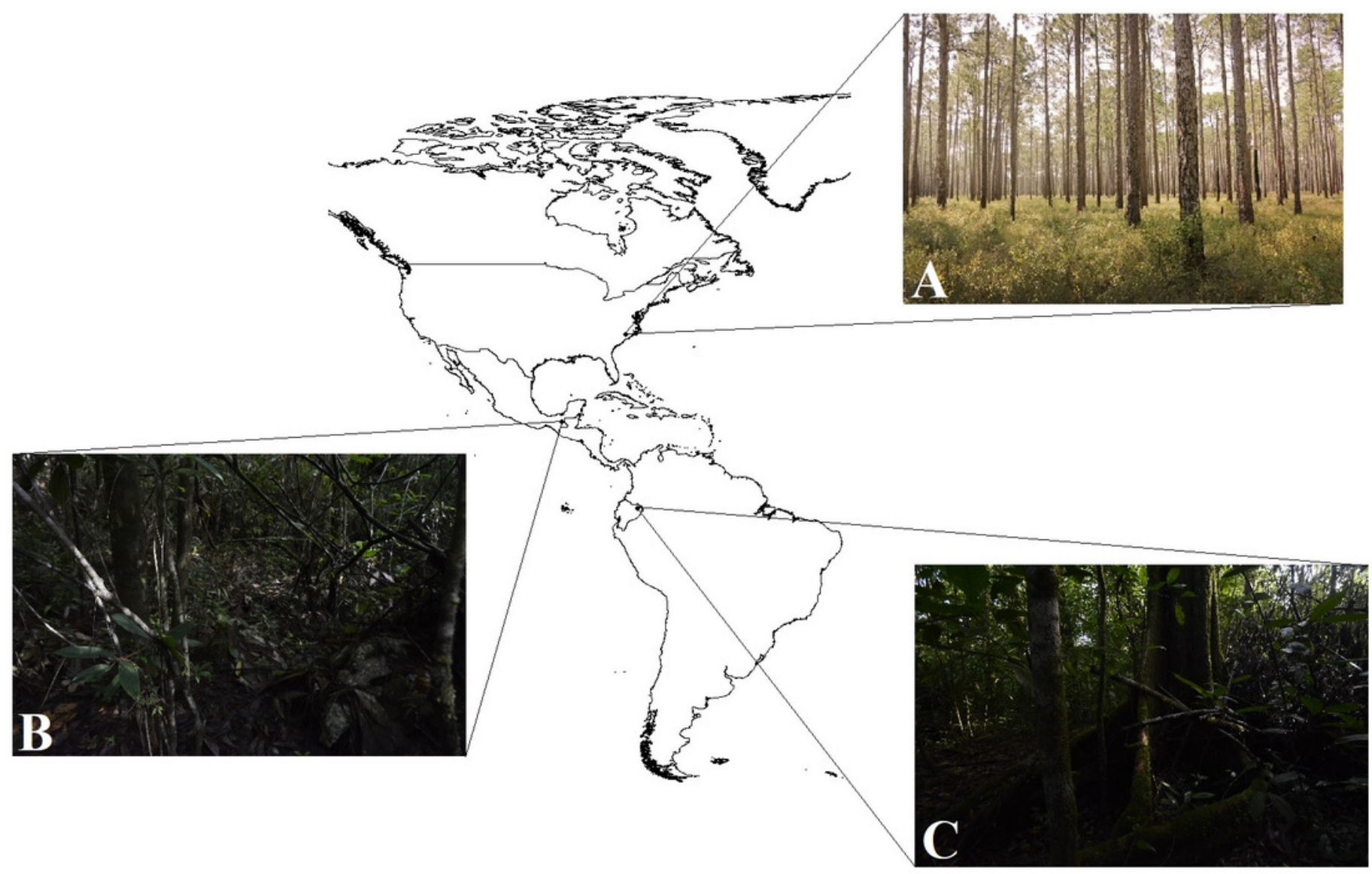


Figure 4

Detection and attack probabilities of avian versus mammalian predators.

The probability that avian versus mammalian predators detected replicas after encounter (A) and attacked replicas after detection (B) across all experimental locations.
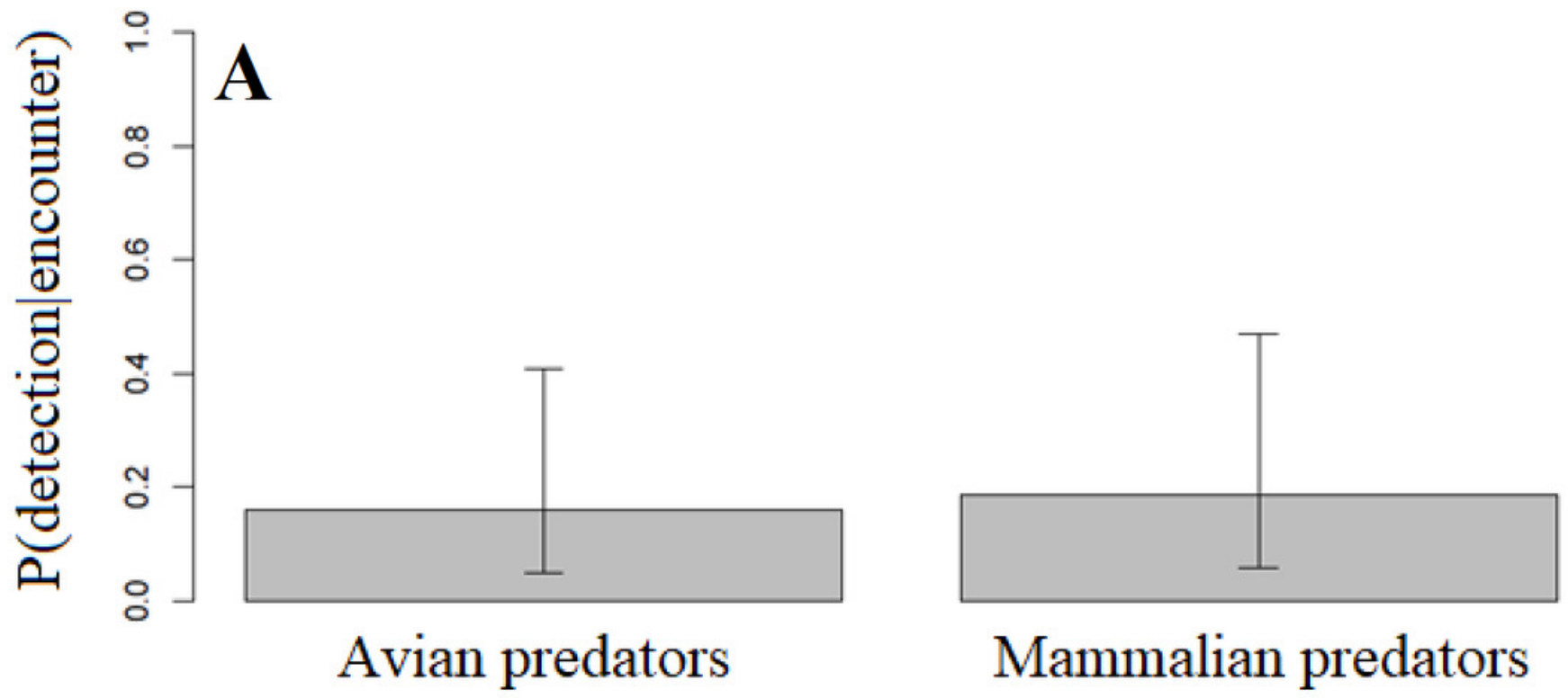

Mammalian predators
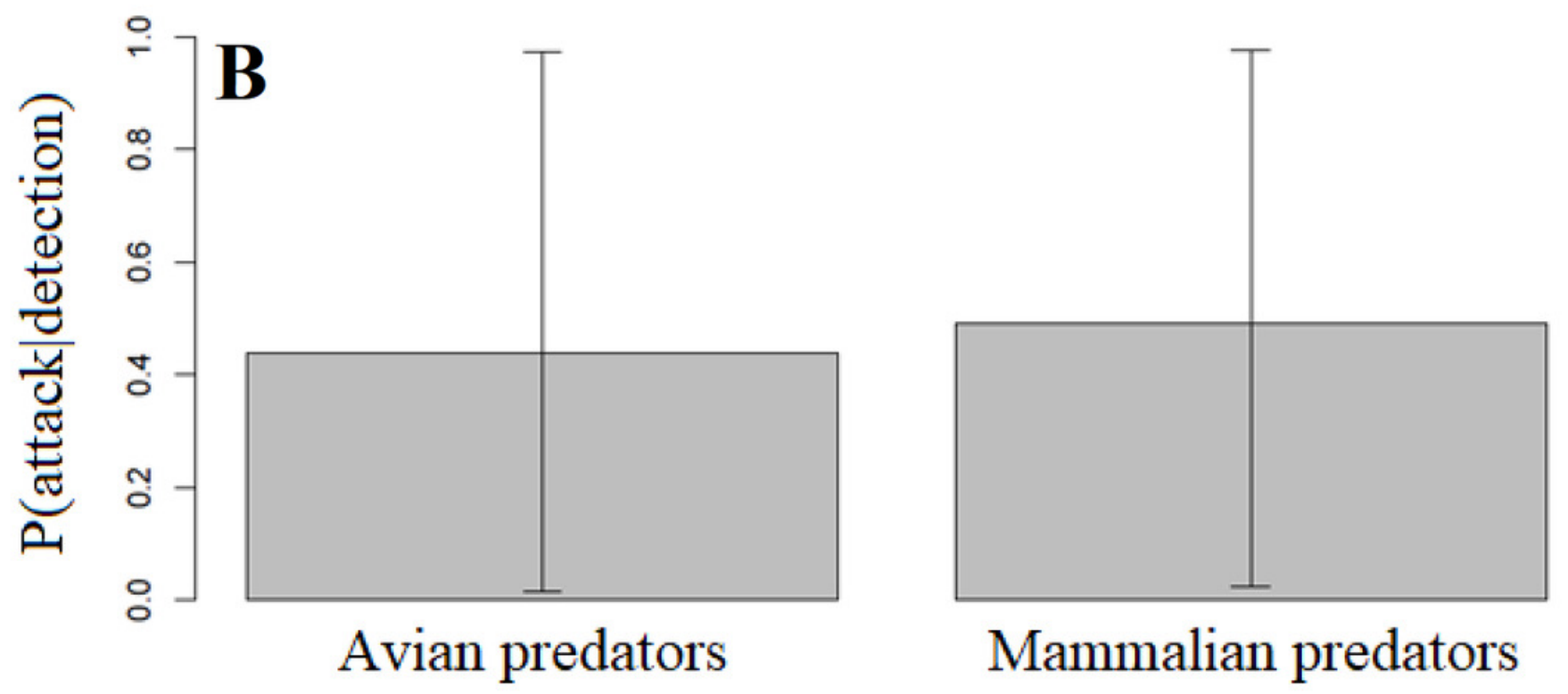


\section{Figure 5}

Temporal activity patterns.

Diurnal patterns in the frequency of encounters (A), detections (B), and attacks $(C)$ in field experiments conducted in Ecuador, Mexico, and North Carolina, USA. Daytime ran from 6 to 18, 6 to 19, and 8 to 17 hours in Ecuador, Mexico, and North Carolina, USA, respectively. 

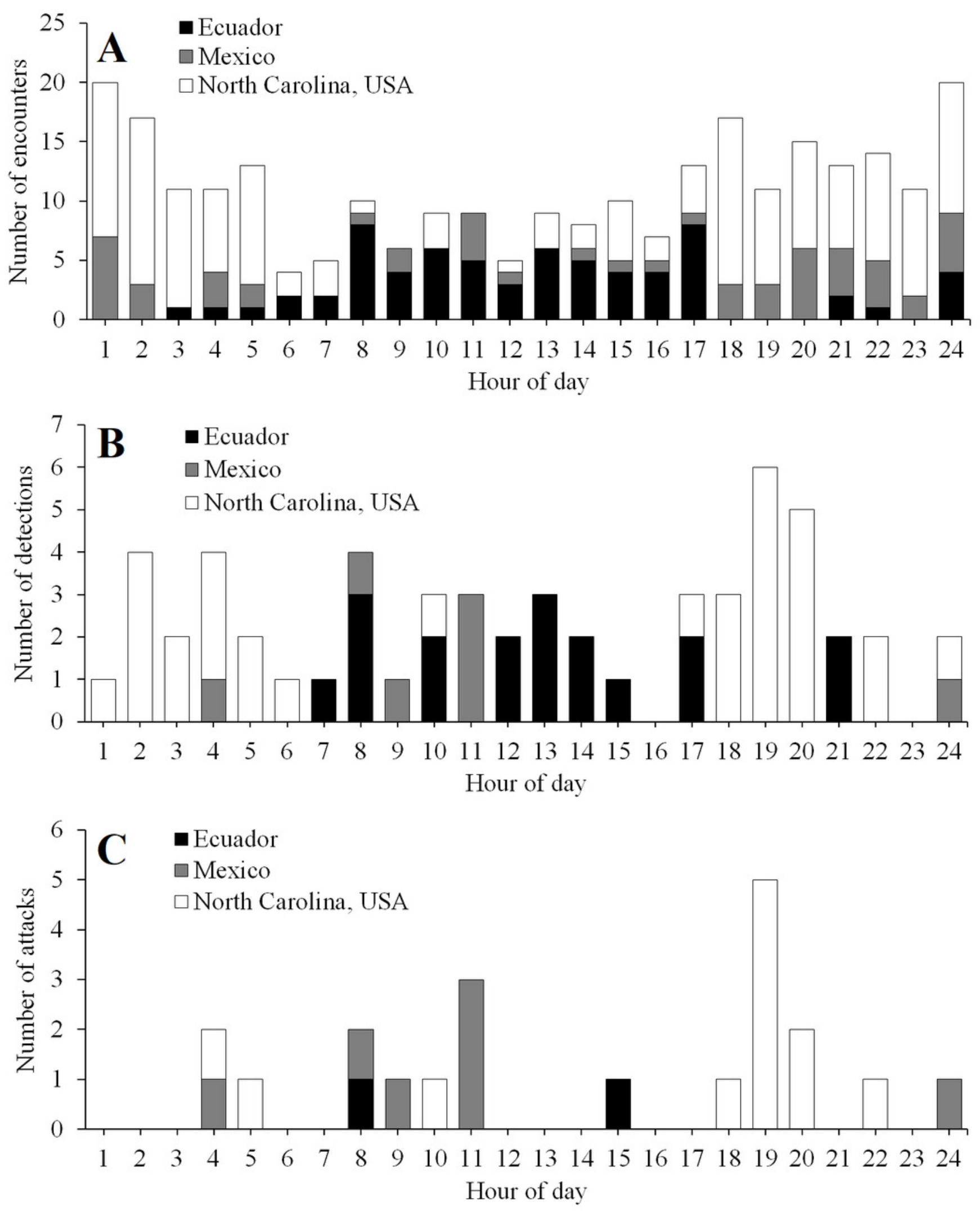


\section{Figure 6}

Results of field experiments.

Numbers of replicas-both with and without camera traps-that bore marks indicative of attacks by avian and mammalian predators as well as numbers of replicas that were missing (i.e., no trace of replica found) in field experiments conducted in Ecuador, Mexico, and North Carolina, USA.

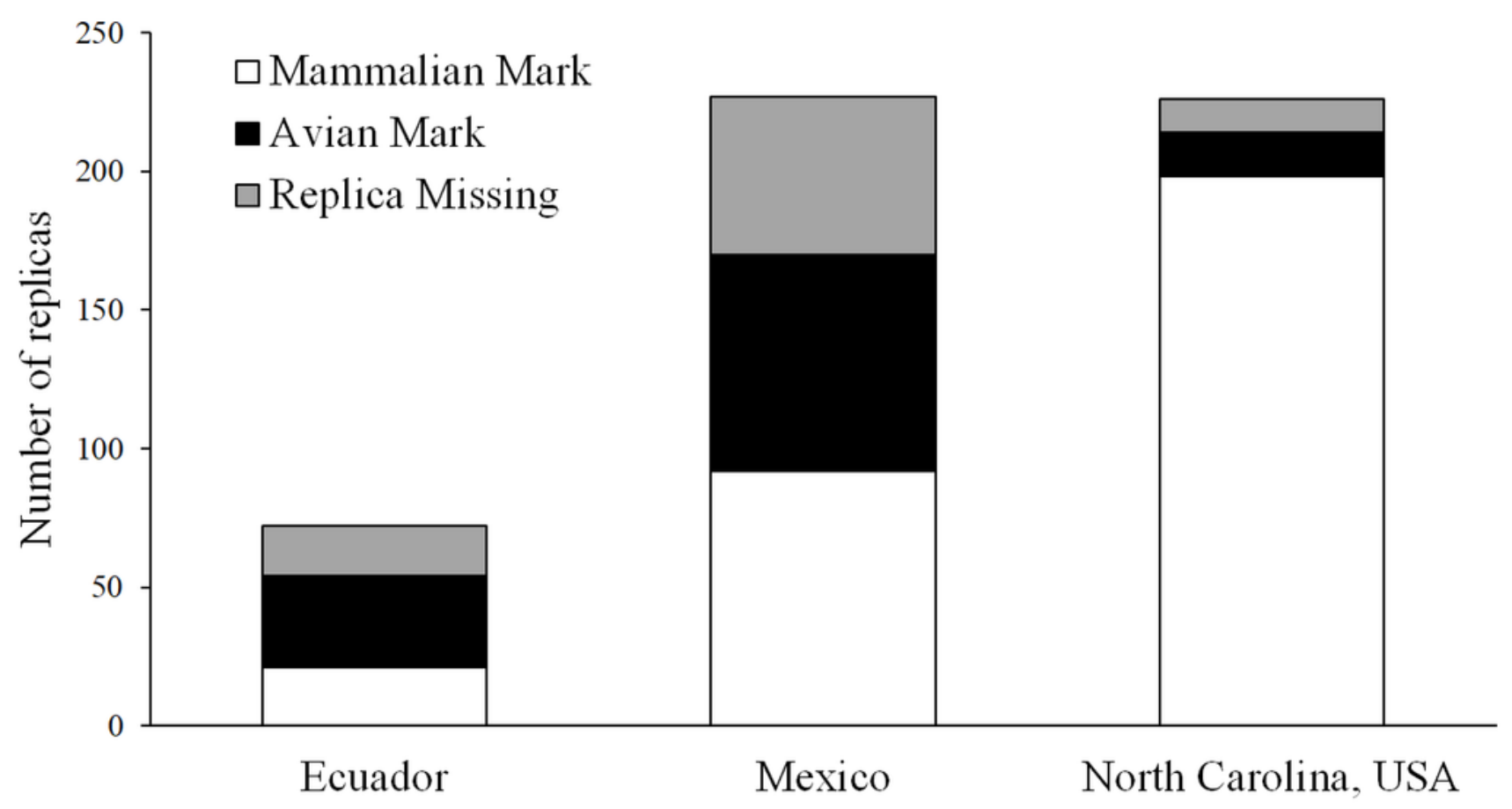


Figure 7

Camera trap observations.

Numbers of encounters, detections, and attacks by avian and mammalian snake predators observed from camera trap videos at each experimental location: Ecuador (EC), Mexico (MX), and North Carolina, USA (NC).

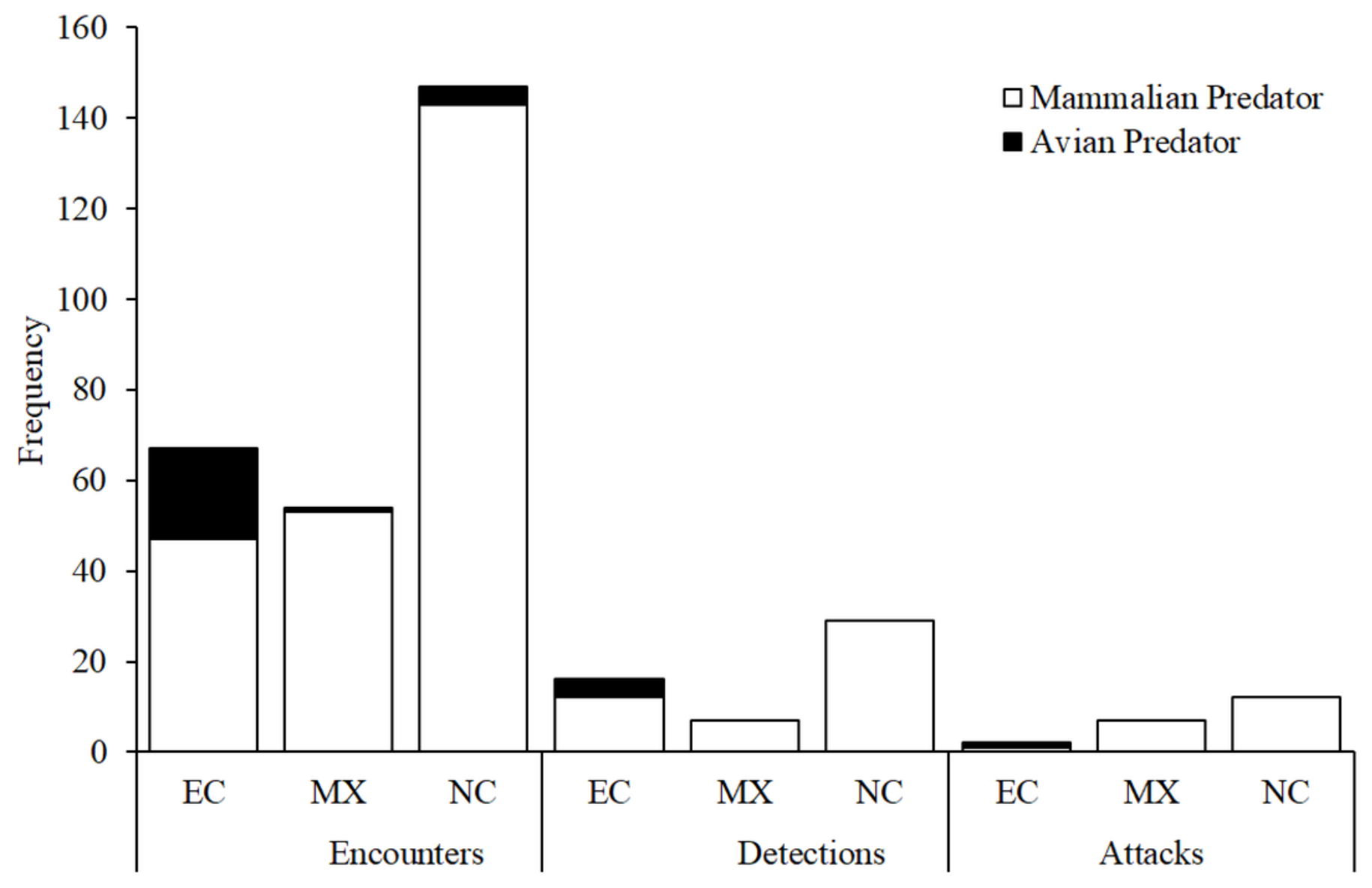




\section{Table $\mathbf{1}$ (on next page)}

Field experiments.

List of characteristics of field experiments that aimed to test hypotheses of aposematism and mimicry in Ecuador, Mexico, and North Carolina, USA. Camera traps were employed at a subset of replicas to collect observational data on predator activity near artificial prey replicas. 


\begin{tabular}{|c|c|c|c|}
\hline & Ecuador & Mexico & North Carolina, USA \\
\hline $\begin{array}{l}\text { Number of } \\
\text { phenotypes }\end{array}$ & $\begin{array}{l}5 \text { ( } 4 \text { Micrurus } \\
\text { variants + brown } \\
\text { control) }\end{array}$ & $\begin{array}{l}4 \text { (3 P. elapoides } \\
\text { variants + brown } \\
\text { control })\end{array}$ & $\begin{array}{l}3 \text { (3 M. fulvius } \\
\text { variants) }\end{array}$ \\
\hline Length of replicas & $165 \mathrm{~mm}$ & $250 \mathrm{~mm}$ & $180 \mathrm{~mm}$ \\
\hline Number of transects & 27 & 35 & 20 \\
\hline $\begin{array}{l}\text { Minimum distance } \\
\text { between transects }\end{array}$ & $200 \mathrm{~m}$ & $200 \mathrm{~m}$ & $3 \mathrm{~km}$ \\
\hline $\begin{array}{l}\text { Placement of replicas } \\
\text { in transects }\end{array}$ & $\begin{array}{l}\text { Singly, along forest } \\
\text { trails, and 1-4 m off } \\
\text { trails on alternating } \\
\text { sides }\end{array}$ & $\begin{array}{l}\text { Singly, along forest } \\
\text { trails, and } 1-4 \text { m off } \\
\text { trails on alternating } \\
\text { sides }\end{array}$ & $\begin{array}{l}\text { Each variant in groups } \\
\text { of three off trails; all } \\
\text { replicas attached to } \\
\text { nails }\end{array}$ \\
\hline $\begin{array}{l}\text { Distance between } \\
\text { replicas or sets of } \\
\text { replicas }\end{array}$ & $5-10 \mathrm{~m}$ & $5-10 \mathrm{~m}$ & $50-75 \mathrm{~m}$ \\
\hline $\begin{array}{l}\text { Replicas with } \\
\text { cameras }\end{array}$ & 37 & 22 & 69 \\
\hline $\begin{array}{l}\text { Replicas without } \\
\text { cameras }\end{array}$ & 1,313 & 1,378 & 531 \\
\hline $\begin{array}{l}\text { Days replicas without } \\
\text { cameras left in field }\end{array}$ & 6 & 12 & 28 \\
\hline $\begin{array}{l}\text { Days replicas with } \\
\text { cameras left in field }\end{array}$ & 6,8, or 14 & 30 & 28 \\
\hline Replica days & 8,356 & 17,196 & 16,800 \\
\hline $\begin{array}{l}\text { Interval replicas were } \\
\text { checked }\end{array}$ & 2 days & 6 days & $\begin{array}{l}\text { Replicas not checked } \\
\text { during experiment }\end{array}$ \\
\hline
\end{tabular}




\section{Table 2 (on next page)}

Predator species.

Frequency of encounters, detections, and attacks by each snake predator species observed from camera trap videos during three field experiments conducted in Ecuador, Mexico, and North Carolina, USA, that were aimed to test hypotheses of aposematism and mimicry. Nomenclature follows Ridgely and Greenfield (2001), Wilson and Reeder (2005), Peterson (2010), and Vallely and Dyer (2018). 


\section{Ecuador}

\begin{tabular}{|c|c|c|c|c|}
\hline Family & Common Name (Scientific Name) & Encounters & Detections & Attacks \\
\hline Bucconidae & Brown nunlet (Nonnula brunnea) & 2 & & \\
\hline Tayassuidae & Collared peccary (Peccari tajacu) & 26 & 11 & \\
\hline Dasypodidae & Giant armadillo (Priodontes maximus) & 1 & & \\
\hline Psophiidae & $\begin{array}{l}\text { Gray-winged trumpeter (Psophia } \\
\text { crepitans) }\end{array}$ & 16 & 4 & 1 \\
\hline Dasypodidae & $\begin{array}{l}\text { Nine-banded armadillo (Dasypus } \\
\text { novemcinctus) }\end{array}$ & 6 & 2 & \\
\hline Felidae & Ocelot (Leopardus pardalis) & 2 & & \\
\hline Tayassuidae & Peccary sp. & 8 & & \\
\hline Accipitridae & $\begin{array}{l}\text { Slate-colored hawk (Buteogallus } \\
\text { schistaceus) }\end{array}$ & 2 & & \\
\hline \multirow[t]{2}{*}{ Tayassuidae } & White-lipped peccary (Tayassu pacari) & 4 & 1 & 1 \\
\hline & Total & 67 & 18 & 2 \\
\hline \multicolumn{5}{|c|}{ Mexico } \\
\hline Family & Common Name (Scientific Name) & Encounters & Detections & Attacks \\
\hline Didelphidae & $\begin{array}{l}\text { Common opossum (Didelphis } \\
\text { marsupialis) }\end{array}$ & 19 & 1 & 1 \\
\hline Procyonidae & Common racoon (Procyon lotor) & 1 & & \\
\hline Canidae & Gray fox (Urocyon cinereoargenteus) & 8 & 6 & 6 \\
\hline Mephitidae & Hooded skunk (Mephitis macroura) & 1 & & \\
\hline Felidae & Jaguarundi (Puma yagouaroundi) & 1 & & \\
\hline Momotidae & Lesson's motmot (Momotus lessonii) & 1 & & \\
\hline Dasypodidae & $\begin{array}{l}\text { Nine-banded armadillo (Dasypus } \\
\text { novemcinctus) }\end{array}$ & 12 & & \\
\hline Felidae & Ocelot (Leopardus pardalis) & 8 & & \\
\hline Mustelidae & Tayra (Eira barbara) & 2 & & \\
\hline Procyonidae & White-nosed coati (Nasua narica) & 1 & & \\
\hline
\end{tabular}




\begin{tabular}{|c|c|c|c|c|}
\hline & Total & 54 & 7 & 7 \\
\hline \multicolumn{5}{|c|}{ North Carolina, USA } \\
\hline Family & Common Name (Scientific Name) & Encounters & Detections & Attacks \\
\hline Corvidae & $\begin{array}{l}\text { American Crow (Corvus } \\
\text { brachyrhynchos) }\end{array}$ & 2 & & \\
\hline Ursidae & Black bear (Ursus americanus) & 19 & 7 & 5 \\
\hline Procyonidae & Common racoon (Procyon lotor) & 80 & 17 & 4 \\
\hline Canidae & Gray fox (Urocyon cinereoargenteus) & 29 & 5 & 2 \\
\hline Didelphidae & Virginia opossum (Didelphis virginiana) & 15 & 3 & 1 \\
\hline \multirow[t]{2}{*}{ Phasianidae } & Wild Turkey (Meleagris gallopavo) & 2 & & \\
\hline & Total & 147 & 32 & 12 \\
\hline
\end{tabular}




\section{Table 3(on next page)}

Camera trap observations.

Frequency of encounters, detections, and attacks are in behavior/100 camera days (total number of observations is given in parentheses). Number of camera days is given below the site headings. Numbers of encounters, detections, and attacks are based on records separated by at least 30 min (for a given species at a given site). 


\begin{tabular}{|c|c|c|c|c|}
\hline & Ecuador & Mexico & North Carolina & Total \\
\hline & 402 & 630 & 504 & 1,536 \\
\hline Predator encounters & $16.7(67)$ & $8.6(54)$ & $29.2(147)$ & $17.4(268)$ \\
\hline Mammalian predator encounters & $11.7(47)$ & $8.4(53)$ & $28.4(143)$ & $15.8(243)$ \\
\hline Avian predator encounters & $5.0(20)$ & $0.2(1)$ & $0.8(4)$ & $1.6(25)$ \\
\hline Detections & $4.0(16)$ & $1.1(7)$ & $6.3(32)$ & $3.4(52)$ \\
\hline Mammalian predator detections & $3.0(12)$ & $1.1(7)$ & $6.3(32)$ & $3.1(48)$ \\
\hline Avian predator detections & $1.0(4)$ & & & $0.3(4)$ \\
\hline Attacks & $0.5(2)$ & $1.1(7)$ & $2.4(12)$ & $1.4(21)$ \\
\hline Mammalian attacks & $0.2(1)$ & $1.1(7)$ & $2.4(12)$ & $1.3(20)$ \\
\hline Avian attacks & $0.2(1)$ & & & $0.1(1)$ \\
\hline $\begin{array}{l}\text { Attacks recorded on clay but not } \\
\text { cameras }\end{array}$ & $0.2(1)$ & & $0.99(5)$ & $0.39(6)$ \\
\hline $\begin{array}{l}\text { Attacks recorded on cameras but } \\
\text { not clay }\end{array}$ & $0.5(2)$ & $0.63(4)$ & $0.4(2)$ & $0.52(8)$ \\
\hline $\begin{array}{l}\text { Attacks recorded on both cameras } \\
\text { and clay }\end{array}$ & & $0.48(3)$ & $1.98(10)$ & $0.78(12)$ \\
\hline $\begin{array}{l}\text { Number of replicas with functional } \\
\text { cameras }\end{array}$ & 34 & 21 & 54 & 109 \\
\hline Number of undetected replicas & 24 & 14 & 29 & 67 \\
\hline $\begin{array}{l}\text { Number of marks on replicas with } \\
\text { cameras }\end{array}$ & & 3 & 15 & 18 \\
\hline
\end{tabular}

